\title{
The Ideas of Sustainable and Green Marketing Based on the Internet of Everything-The Case of the Dairy Industry
}

\author{
Hamed Nozari ${ }^{1}{ }^{(1)}$, Agnieszka Szmelter-Jarosz ${ }^{2, *(1)}$ and Javid Ghahremani-Nahr ${ }^{3}(\mathbb{C}$ \\ 1 Department of Industrial Engineering of Central Tehran Branch, Islamic Azad University, \\ Tehran 1469669191, Iran; ham.nozari.eng@iauctb.ac.ir \\ 2 Department of Logistics, Faculty of Economics, University of Gdańsk, Armii Krajowej 119/121, \\ 81-824 Sopot, Poland \\ 3 Faculty member of ACECR, Development and Planning Institute, Tabriz 5154837693, Iran; \\ javid.ghahremani@yahoo.com \\ * Correspondence: agnieszka.szmelter-jarosz@ug.edu.pl
}

Citation: Nozari, H.; Szmelter-Jarosz, A.; Ghahremani-Nahr, J. The Ideas of Sustainable and Green Marketing Based on the Internet of EverythingThe Case of the Dairy Industry. Future Internet 2021, 13, 266. https:// doi.org/10.3390/fi13100266

Academic Editor: Carmen de Pablos Heredero

Received: 21 September 2021

Accepted: 8 October 2021

Published: 19 October 2021

Publisher's Note: MDPI stays neutral with regard to jurisdictional claims in published maps and institutional affiliations.

Copyright: $\odot 2021$ by the authors. Licensee MDPI, Basel, Switzerland. This article is an open access article distributed under the terms and conditions of the Creative Commons Attribution (CC BY) license (https:// creativecommons.org/licenses/by/ $4.0 /)$.

\begin{abstract}
The use of advanced computer technologies has dramatically changed marketing. Concepts such as smart, sustainable, and green marketing have emerged in the last 20 years. One of these new technologies is the Internet of Things (IoT), which has led to the development of the activities and performances of industries in various dimensions. For the various objects, such as people, processes, and data, involved in marketing activities, the Internet of Everything (IoE) as an evolved IoT is a possible future scenario. Some sectors pretend to be the first to implement this, and the more they rely on dynamic, unstable customer needs, the better a solution the IoE is for them. Therefore, this paper presents a clear vision of smart, sustainable marketing based on the IoE in one of the fast-moving consumer goods (FMCG) industries, the dairy industry. Key factors are identified to help readers understand this concept better. The expert interview makes it possible to draw a picture of the factors that have helped successfully implement the IoE in the dairy sector.
\end{abstract}

Keywords: sustainable marketing; green marketing; Internet of Things (IoT); Internet of Everything (IoE); green marketing

\section{Introduction}

The development of environmental awareness has become a worldwide phenomenon [1,2]. As a result, businesses have begun responding to environmental challenges using green marketing strategies, which are part of sustainable development strategies. Since the 1980s, ecological issues such as global warming, greenhouse effects, pollution, and climate change have been directly linked to industrial production [3]. Currently, almost all companies and organizations have their own green development visions. They are visible in the published sustainability reports $[4,5]$. It is thus natural that businesses in almost every industry consider aspects of "environmental sustainability" when designing their products and services. One of its elements is sustainable marketing.

Sustainable marketing involves the development and promotion of products and services that meet customers' needs in terms of quality, efficiency, price, and convenience without having a detrimental effect on the environment, society, or economy. It involves high technologies that communicate the offer and promote sustainable lifestyles and operations in companies [6].

Technology in the modern age is one of the enablers helping to create value for the customer [7]. Data are one of the most essential factors in improving the marketing environment and technologies have created different ways of producing data [8]. Using these data can positively impact the growth of business activities and help customers achieve their desires and obtain the best products and services. Today, a variety of social networks and mobile applications act as "social sensors" by expressing people's emotions 
and interacting with them together [9]. The data produced on people's opinions and desires are a low-cost resource for designing marketing activities. All of these aspects, along with the need for real-time analysis, relate to big data management in marketing.

The IoT is one of the most important big data sources, so it is a potentially good solution for achieving marketing goals. This technology was first introduced in 1999 by Kevin Ashton. He described a world where everything had a digital identity and was managed by computers [10]. The advent of the IoT has changed many concepts, one of which is "smart marketing". The most critical changes to smart marketing have occurred in the form of Internet-enabled smart devices, which can send and receive vast amounts of data from key sources that affect the business environment [11]. If something integrates people, processes, data, and other objects in any configuration, it can be considered part of the Internet of Everything (IoE). As it is understood, this technology connects an extensive range of technologies in order to create more and better marketing communication.

However, the field of IT solutions in sustainable or green marketing has scarcely been investigated in the literature. The use of digital solutions in marketing, which is also called "smart marketing", was examined by Ziółkowska with regard to small and medium enterprises (SMEs) [12]. She indicated that the IoT is one of the most promising marketing tools and defined current marketing as "Marketing 4.0". Similarly, Saura et al. examined data analysis from the point of view of social media (but mostly from the points of view of ethics and law) [13]. In turn, Bhavana and Thiruchanuru presented green marketing from the perspective of the customer's decision-making processes [14]. However, they did not write about digital solutions. Additionally, Schmitt proved that positive attitudes towards sustainability do not translate into real consumer actions [15].

A few studies have addressed fields of research similar to this study. Weng proved with survey results analysis that there is a "partial mediating effect of marketing intelligence capability in the link between IoT capability and business strategy performance" [16]. Saura et al. described techniques of AI-based CRMs in digital marketing, but only in B2B relations [17]. The most important sources for confirming the research gaps in digital marketing with regard to sustainability are the papers by Diez-Martin et al. [18] and Saura et al. [19]. They both relate to digital marketing and sustainable strategies. There are also many studies about the IoT. The presented literature addresses neither FMCG goods nor the IoT and its developed form, the IoE, in marketing in FMCG sectors or, specifically, the dairy industry.

This paper tries to partially fill the research gap concerning the use of IT technologies in green-or, broader, sustainable-marketing in the dairy industry. Generalizations about the whole of the FMCG part of the market are not possible because there is no ideal solution for all the sectors due to their specificities. Therefore, this paper only focuses on the chosen sector.

This study investigates the significance (importance) of factors affecting green marketing based on the IoE. The conceptual framework of the IoE in green marketing is presented as well. The originality of this paper lies in its topic (filling the research gap) and the research framework. This framework combines two methods, namely, a case study and expert interviews. The importance of some of the factors involved in building green marketing with the IoE approach is difficult to assess based on quantitative data, e.g., consumer surveys. Therefore, it was assumed that the experts would know the industry the best and be in the best position to assess the factors.

To achieve the research goal, the paper is structured as follows. Section 2 presents a literature review in terms of sustainable marketing, green marketing, and the Internet of Everything. The next section describes the research approach, highlighting the characteristics of the case study, the expert interviews, and the data analysis. In Section 4, the ecosystem of green marketing, based on the IoE, technologies, opportunities, and challenges, is described. This part contains the research findings finalized in the form of a conceptual model. Section 5 discusses the results. Lastly, the conclusions are presented in Section 6. 


\section{Literature Review}

\subsection{Sustainable Marketing}

Since digital transformation currently affects different types of businesses [20-22], the value chains must be redetermined [23]. Regardless of the level of transformation, it can play a crucial role in almost every branch of the industry [7]. However, digital developments go beyond updating or changing technology. In businesses, the potential for customer acceptance is more significant if they use digital solutions, especially in the era of the COVID-19 pandemic [24]. Therefore, digital tools are required in marketing more than ever [25]. In addition, businesses need to understand customer expectations and consequently develop a rational product or service that meets customer needs.

One of the most important commitments that organizations and companies need to pay particular attention to is the environmental, social, and economic crises faced by the global community [19]. These three mentioned aspects build sustainability [26]. If customers want sustainable businesses (and goods or services), they also require sustainable marketing. As a part of sustainable development, this concept aims to increase productivity to prevent damage to ecosystems or the degradation of natural resources [27]. That is why sustainable marketing is part of the broader sustainable development area. This concept contains marketing in its traditional sense (economic), social marketing, and environmental (green) marketing [28]. It strives to strike a meaningful balance between these three critical areas. It is now recognized as a fundamental requirement for business organizations to move forward [29]. Sustainable marketing involves developing and promoting products and services that meet the customer's needs besides the required quality, efficiency, reasonable price, and convenience without detrimental environmental outcomes.

As shown in Figure 1, sustainable marketing (besides the traditional division into three dimensions: economic, social, and environmental) is based on three pillars. First, it reduces waste and hazards by, e.g., re-using carrier packages and advertising solutions (environmental dimension). Second, sustainable marketing encourages customers by partnering with them and cooperating with other partners (non-profit organizations, local authorities-a social dimension). Companies can rely on critical users and customers to promote and share information through social networking sites. Third, it should support long-term planning (mission of the organization, long-term goals, long-term plans of developing the operation, dissemination strategies, etc.-economic dimension).

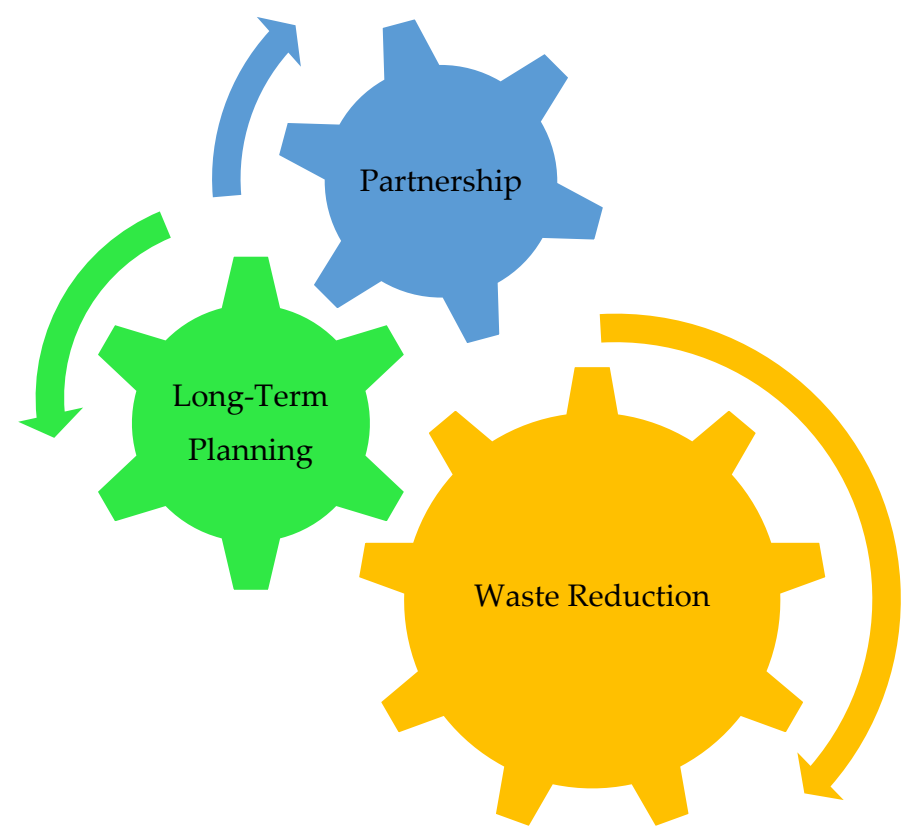

Figure 1. Basic principles of sustainable marketing. 
Since the two concepts, sustainability and green marketing, have been discussed separately in the literature, we tried to present them together in this study.

\subsection{Green Marketing}

A growing interest in green activities in many areas of social and economic life caused many companies to develop their greenness for many reasons, but mainly for financial reasons (building the brand), preserving the depletion of the natural environment, or responding to competitors. Green marketing focuses on marketing activities while protecting the natural environment [30], where the process includes all the traditional marketing activities such as proposing a modification of products, packaging, and labeling and building advertising strategies, but the focus on the environment is much more substantial. First, it covers managing how to deal with the anticipation, identification, and satisfaction of consumers' needs. These activities should bring value and, subsequently, profit. Second, the company must implement substantial environmental changes due to demanding challenges while developing safer products [31].

Because people are currently very concerned about environmental issues, many companies nowadays use green marketing to raise their competitive advantage. Besides, consumers want to pay more to live green [32]; this is both the cause and effect of companies' actions. Customers change their buying habits, trends in the consumer market occur, and they are a basis for changing companies' offers. When the offer changes, more customers are willing to change their buying habits. Consequently, green marketing is a marketing strategy and not only a philosophy or an environmental protection practice. Companies provide green marketing training to provide employees (especially sales representatives) the knowledge of effectively promoting green products by clearly presenting the main message to the consumers [33]. Green marketing includes many business practices analogously to the marketing mix. Hence, companies should adopt a green marketing strategy, including a marketing mix (as in traditional marketing) targeting consumers demands and personalities [34].

The organizations implementing sustainable strategies sent a solid message to the stakeholders regarding the capacity to acknowledge business risks and challenges and adapt to changes in the market. Note that green marketing is a part of this strategy. These organizations align with their specific social needs by transposing "green" marketing in their internal processes. Furthermore, enforcing "green" marketing principles is performed at all the marketing mix components, developing competitive advantages by differentiating the benefits and the targeted organizational culture [28]. As a result, both sides are satisfied: company and customer, and additionally, other stakeholders such as non-government organizations, residents, and others.

\subsection{Internet of Things and Internet of Everything}

The Internet of Things (IoT) is often perceived in the literature as a supporting element to Industry 4.0 and its successors [35]. This idea is based on the communication between objects using the Internet to send and receive messages from other objects. Its development caused "smart" objects to arise, such as machines, houses, factories, etc. Naturally, this communication produces large amounts of data allowing the analysis of people's behavior [36]. Exploiting those datasets is one of the ways for marketing activities to optimize the company's actions to increase the competitive advantage. However, the IoT has changed from 2010, and now the ways of connecting objects are much more developed than at the beginning of the Industry 4.0 era.

The Internet of Everything (IoE) is an advanced form of IoT. Its idea assumes connections among people, processes, data, and objects [37]. IoE was initially defined by CISCO in 2012 as "a network of networks that reunites people, processes, data, and things in network connections more significant and valuable than ever" [38,39]. So, IoE builds an advanced, intelligent network of objects. IoE supports creating new capacities, both for businesses and society [40]. The IoE paradigm covers more than the IoT concept as follows: 
- The Industrial Internet (II), concerned with data of interest to industry;

- The Internet of People (IoP), especially social networks and connections among people;

- Internet of Services (IoS) [41].

Moreover, IoE uses nano-networks to combine nanosensors in various objects. Thus, it offers a new concept that previously seemed impossible as the Internet of Nano-things. Furthermore, IoE allows person-to-person and person-to-machine connections with more valuable connections than machine-to-machine communications [42]. Accordingly, IoE exceeds the relationships of objects and integrates them to build a specific interconnected society. Therefore, intelligent services and things define "everything" in the IoE concept [38].

IoE requires advanced capacities and skills in information sharing. Real-time data are collected from diverse objects and can be extracted and analyzed by IoE tools (usually big data analysis tools). Heterogeneous IoE environments can transform robotic devices and human actors into autonomous service agents. Therefore, the design and implementation of IoE applications have become very complex. To increase the effect, artificial intelligence (AI) can be integrated into smart devices, and then people and things can interrelate appropriately in a multi-user and social context environment [43].

\section{Sustainable Marketing Based on IoE}

Nowadays, data have become ubiquitous: they are everywhere. Gathering data from many dispersed sources and complex analysis allow the design of products to create customer value.

Therefore, the importance of IoE in sustainable (including green) marketing has led to providing a framework for assessing the role of IoT and then IoE in sustainable marketing. The aspects of sustainable marketing presented in the framework of Figure 2 are defined as follows [44]:

- Green marketing (environmental layer of sustainable marketing): developing and promoting environmental sustainability in marketing and company strategy, as well as tactical and operational layers of management (e.g., business processes).

- Social marketing (social layer of sustainable marketing): using marketing tools, communication channels, etc., to encourage sustainable behavior, e.g., green lifestyle, no-waste lifestyle, or to build loyal customer groups identifying with a sustainable development idea, sustainable lifestyle, or sustainable consumerism ethos.

- Critical marketing (economic layer of sustainable marketing): achieving business goals while managing resources efficiently, e.g., closed-loop supply chain, circular economy idea, green (but profitable) innovations, and adjusting the marketing strategy and toolset to this approach.

According to the proposed framework, the most key actors of green marketing are the business sector entities, including social marketing of the citizens, 3rd sector organizations, and critical marketing of markets, systems, institutions, and government. The importance of IoT and IoE tools leads to the development of sustainable marketing (e.g., any consumer application, any business application, any tagging technology, and anything with connectivity). They include many elements, both objects and technologies: smartphones, RFID, NTC, barcodes, QR codes, tablets, etc. Accordingly, the development of sustainable marketing [45] leads to the following results:

- Community building means developing new communities focused on users of particular devices, allowing for publishing content on social media. It facilitates targeting the marketing content for those groups.

- The rise of conversational commerce keeps in touch with potential customers by using chatbots, intelligent assistants, and smart speakers. They allow shopping online, checking order status, and locating stores, restaurants, events, etc.

- Data availability: IoE devices generate a large amount of real-time data from many sources. Data availability will let marketers test out new ideas and tools for big data analysis. 


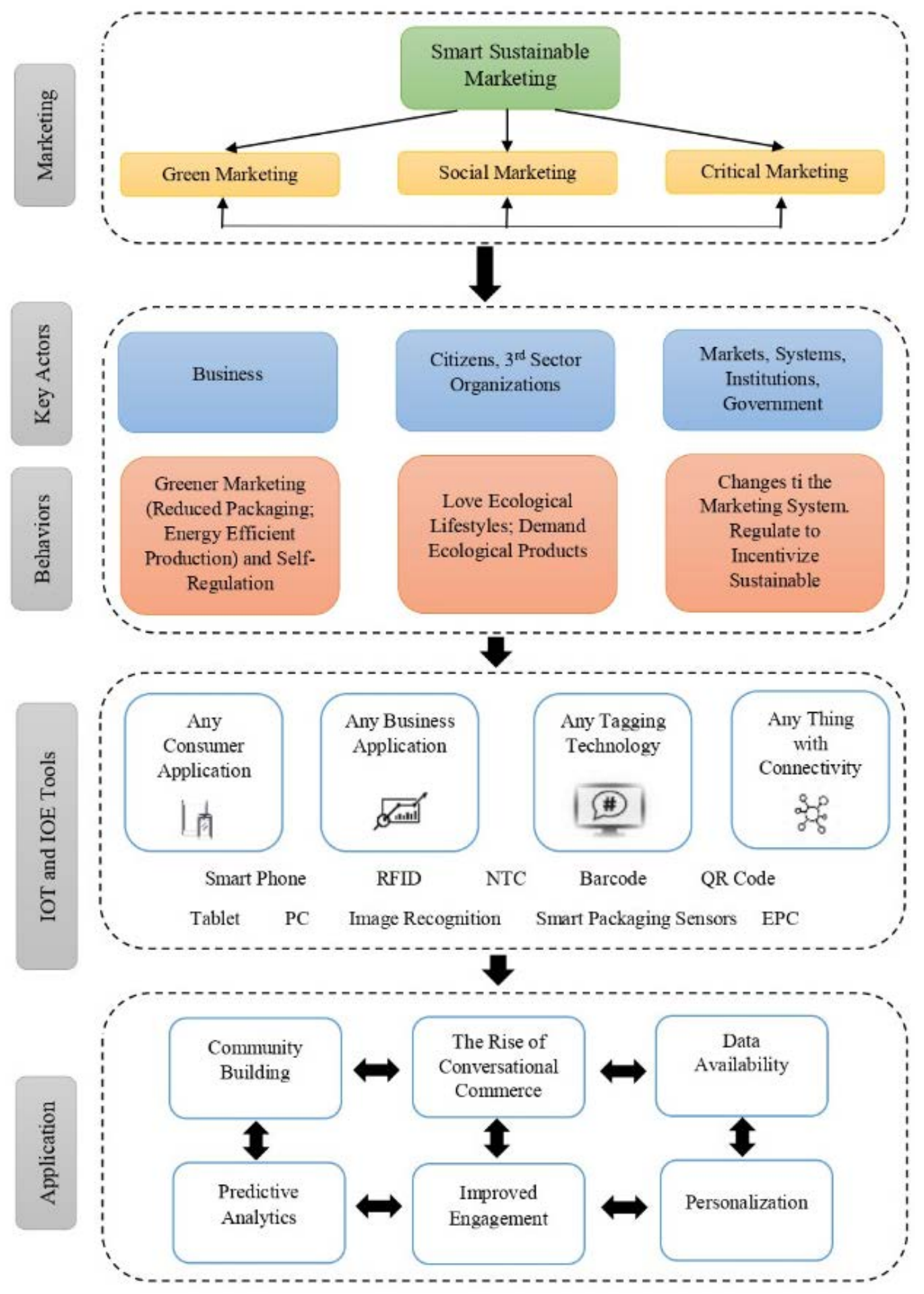

Figure 2. The framework of smart sustainable marketing based on the IoE.

- Predictive analysis: Tracking data from many data points requires ordering them, verification, analysis, and then prediction. Predictive analytics measures and analyzes users' present and past purchase patterns, attitudes, behaviors, and location details and suggests their future choices. This will transform the company's marketing into the proactive mode from the reactive mode.

- Personalization: Marketers use communication such as targeted email campaigns, videos, and product and push notifications to deliver a personalized marketing experience for all users of the application-former and potential customers. CRMs 
(Customer Relationship Management) can be practical tools to obtain the correct and complete data.

- Improved engagement: All the above elements provide an essential finding: IoE allows marketers to show highly relevant content to their audience. People are flooded by the information from online and offline channels throughout the day. Then, naturally, most of the ads are ignored. IoE devices may help marketers understand their audience pinpoint; marketers can reach them successfully with highly targeted content.

This literature review served as a basis for preparing the list of the most critical factors (criteria) in sustainable marketing. Due to the inconsistency of approaches of different researchers, the authors of this paper unified the list of criteria and sub-criteria, using the broadest set of them identified in the literature. When the same sub-criterion was assigned to different criteria, it was finally assigned to the criterion based on the most common approach in the literature. The following part of the paper examines the most important criteria and sub-criteria for influencing sustainable marketing using the IoT. Based on this, three main criteria and 11 main sub-criteria of identification have been reviewed for effectiveness (see Table 1).

Table 1. Summary of the most important criteria and sub-criteria in sustainable marketing.

\begin{tabular}{|c|c|}
\hline Criteria & Sub-Criteria \\
\hline Technological factors & $\begin{array}{l}\text { Usefulness } \\
\text { Reliability } \\
\text { Cost efficiency } \\
\text { Standardization }\end{array}$ \\
\hline Market factors & $\begin{array}{c}\text { Demand } \\
\text { User acceptance } \\
\text { Business models } \\
\text { Building ecosystem }\end{array}$ \\
\hline Legal factors & $\begin{array}{c}\text { Industry-specific } \\
\text { Consumer protection-specific } \\
\text { Government-specific }\end{array}$ \\
\hline
\end{tabular}

\section{Method}

\subsection{Case Study}

The case study is a popular and underrated but at the same valuable research method in social sciences [46], and also in the area of supply chain management (SCM) [47,48]. Due to the different regional implications, it is also used in the case of SCM or sustainability in FMCG industries [49-51]. There has also been case study-based research in sustainable marketing and IoE-related literature [52]. Field benchmarks provide valuable insights to the knowledge about IoE and IoT in FMCG industries [53]. However, FMCG consists of many industries, so the case study method is justified only when some interesting, specific, or typical case is described [54]. Moreover, diverse characteristics of possible cases enable the use of the case study method [55]. Nevertheless, the role of the case study method in building theory is undisputed when the research plan is robust [56].

The research plan was set up based on a few literature sources and consisted of the elements as follows [46,55]:

1. Initial source review, defining the exact research problem;

2. Choosing the FMCG industry;

3. Choosing the research method;

4. Designing the expert interview;

5. Recruiting the experts;

6. Conducting the interviews;

7. Analysis of results; 
8. Preparing the report (paper), including discussing the results and theoretical and practical implications.

According to the chosen research method, this study is exploratory and descriptive [57]. The reason for choosing FMCG industries, specifically the dairy industry, was due to the daily use of products, the vital role of products in people's everyday lives, and the short lifecycle of products and short shelf life [58]. The other cause of the interesting nature of this industry was its high vulnerability to the changes initiated by the COVID-19 pandemic [59], which resulted from the specifics of the products offered. Because of the changes in supply chains in the dairy industry and uncertainty about the size of the demand [60], even if dairy products are one of the necessities, IoT and its developed form, IoE, seemed to be one of the possible solutions.

Using IoE technology, several sensors can communicate with a person or other devices and exchange data. In the case of implementing the IoE in the dairy industry (the whole supply chain [61]), the devices are present or will be present in homes (for example, smart stoves, smart TVs, etc.). IoE can be very useful for marketing in various industries, especially FMCG industries, because it can improve the e-shopping market and provide valuable features even for traditional users. The dairy industry is one of the sectors in the FMCG industry that is closely related to people's daily lives, and their maintenance can be subject to the use of smart tools such as smart refrigerators and smart stoves. When combined with digital services, these physical products, besides developing a way of doing things, create an interaction with the consumer. Some of these objects allow the individual to receive customized services.

These products are among people's daily needs, and therefore their constant presence in the family basket can be significant. For example, most people consume dairy products such as milk, cheese, and butter daily. Using IoE-based systems allows people, e.g., to buy homemade items at the push of a button on cell phones. Therefore, it enables people to save maximum time and money.

\subsection{Expert Interview}

The whole part of the expert interview was made based on one approach [62]. It was assumed that the active specialists related to implementing marketing strategies know their industry well. Experience in IoT-related marketing activities was required. Therefore, they were selected as the statistical population or the interviewees identified based on the professional database. To conduct the research, purposeful sampling was conducted. It was assumed that if the experts who agreed to the interview were not sufficient, they would contact others (snowball sampling). After the verification of the new contacts (if they met the entry criteria), they were included in the interview [63]. This type of sampling is called network sampling [64]. According to the research framework, a semi-structured questionnaire was designed for the interviewer. During the interview, six questions of the semi-structured questionnaire were used to guide the interview and collect data.

The highest priority was to meet the standards of data adequacy and saturation. In this study, from the 32nd interview onwards, in practice, the richness needed to end data collection was obtained, and it was ensured that the data would be repetitive from then on. However, to ensure data collection, it continued until the 40th interview. In other words, the theoretical saturation in this study occurred when researchers did not expect to find new data and articulate a new strategy in future discussions. At the same time, the categories had reached the necessary richness desired by the researchers. Due to the diversity of the types mentioned and according to the method [65], the researchers concluded that the desired final result could be confirmed through the information obtained.

It was crucial to ensure and check if the chosen experts have a brilliant track record in marketing in the dairy industry and are fully acquainted with IoE technology. Therefore, the minimal inclusion criteria for the experts' group were: a minimum of five years of professional experience in marketing, a minimum of three years of professional experience in the marketing of dairy products, and direct influence on marketing content. In addition, 
the tasks within the position occupied could be diverse, also creating SEO-related issues. The characteristics of the selected group of experts are shown in Table 2.

Table 2. The structure of the expert's group.

\begin{tabular}{ccccccc}
\hline \multicolumn{2}{c}{ Gender } & \multicolumn{2}{c}{ Age Range } & \multicolumn{3}{c}{ Occupational Status } \\
\hline Male & Female & $28-35$ & $36-45$ & Marketing Director & IT Manager & Marketer \\
\hline 25 & 15 & 29 & 11 & 15 & 11 & 14 \\
\hline
\end{tabular}

As mentioned, the experts were recruited using the contact information obtained from the professional database (the academic institution had access to the professional, commercial database with companies' data). After contacting the potential experts and presenting the basic information about the short interview, the potential expert was asked to participate in the research. If the experts met the basic inclusion requirements, they were qualified for the interview. The interview was carried out in June and July 2021. Firstly, it was an open conversation with the potential experts about the IoE knowledge and marketing tasks they are responsible for. Then, the questionnaires were sent to them (see Section 4.3). Then, the interviews were carried out. Finally, in this study, 40 experts active in 25 dairy companies were interviewed.

\subsection{Data Analysis}

In the analysis of IoE in food industries [52,66,67], the four areas of impact were identified (see Table 3): smart CRM systems for creating and maintaining relations with direct customers, smart packaging (enabling the use of barcodes, RFID, QR codes, and others; the more solutions, the better), smart equipment at home (e.g., to manage the temperature in the fridge), and predictive social media (to gather and analyze data and predict future demand and then adjust the content to the receiver). Performance, activity, and facilitation factors potentially impacted IoE development in this particular industry [68-72].

Table 3. Factors influencing IoE-based marketing in the dairy industry.

\begin{tabular}{cc}
\hline Factor & Area of Impact \\
\hline Performance & Smart CRM \\
Smart packaging \\
& Smart equipment in homes \\
Predictive social media \\
Activity & Smart CRM \\
& Smart packaging \\
& Smart equipment in homes \\
& Predictive social media \\
\hline Facilitation & Smart CRM \\
& Smart packaging \\
& Smart equipment in homes \\
& Predictive social media \\
\hline
\end{tabular}

To analyze the data obtained from semi-structured interviews with entrepreneurs, an open, axial, and selective coding method (thematic analysis method) has been used [73,74]. The coding process began with open coding. For this, the information was first segmented, and then the terms were categorized into synonymous units to add concepts to them. The next step, called axial coding, was to review and differentiate the classes that resulted from the open coding. From many organized types, the most appropriate were selected. The most relevant classes to the research question in axial coding were selected through extended codes and related code points [75]. Many items were then searched in the text as related codes to describe the pivot class. Finally, selective coding continues axial coding 
at a higher level. This step usually aims to describe the central class around which other relevant classes can be classified.

A fuzzy 5-level Likert scale was used to register the effect of the parameters based on expert opinions; after identifying the effective criteria and establishing the expert's group (see Section 4.2), the short questionnaires were sent to them. The linguistic variables presented in Table 4 were used to express the importance of each indicator. In this research, fuzzy triangular numbers have been used (as shown in Table 4). Fuzzy triangular-based methods are the most significant ones used in scientific research [76-80], even for supply chain-related research in COVID-19 pandemic times [81]. Thus, it was recognized as the best solution for data analysis in this paper.

Table 4. Linguistic variables and fuzzy Delphi numbers.

\begin{tabular}{cc}
\hline Linguistic Variable & Fuzzy Triangular Numbers \\
\hline Very little & $(0,0,0.25)$ \\
Low & $(0,0.25,0.5)$ \\
Medium & $(0.25,0.5,0.75)$ \\
High & $(0.5,0.75,1)$ \\
Very high & $(0.75,1,1)$ \\
\hline
\end{tabular}

\section{Results}

Table 5 presents the factors influencing the use of IoE on dairy marketing using expert opinions. In analyzing the Likert scale questionnaire results, determining the mean for the data is not very effective. In such a case, the analysis of the results can be performed based on the "frequency of responses" and determining the "most common response" (see Appendix A, Table A1).

Table 5. Factors' impact rate of IoE-based marketing in the dairy industry.

\begin{tabular}{ccc}
\hline Factor & Area of Impact & Impact Rate \\
\hline \multirow{2}{*}{ Performance } & Smart CRM & $80 \%$ \\
& Smart packaging & $75 \%$ \\
& Smart equipment in homes & $85 \%$ \\
& Predictive social media & $75 \%$ \\
\hline Activity & Smart CRM & $82 \%$ \\
& Smart packaging & $80 \%$ \\
& Smart equipment in homes & $81 \%$ \\
& Predictive social media & $90 \%$ \\
\hline Facilitation & Smart CRM & $81 \%$ \\
& Smart packaging & $80 \%$ \\
& Smart equipment in homes & $78 \%$ \\
\hline
\end{tabular}

Based on expert opinions on the impact of criteria and sub-criteria on sustainable marketing based on IoE, it was found that the market factor (performance) with a weight of 0.3985 has the most critical impact on sustainable marketing. The second most important was the activity, and the third was facilitation.

The results in Table 5 show that social networking tools have the most significant impact on marketing activities. As can be seen in this table, the activity and predictive capabilities of social media as one of the most effective tools of IoE in today's world have the highest impact on sustainable marketing activities. They can play a decisive role in the sustainability of the dairy industry's marketing ecosystem, which seems obvious given the high penetration rate of these technologies. Intelligence in customer relationship management systems also prioritizes sustainable optimal performance in IoE-based marketing [36]. They are also powerful and valuable facilitators. Additionally, smart home appliances 
such as smart TVs, smart refrigerators, smart stoves, and sensors in smart homes have the highest impact factor on powerful, sustainable marketing performance.

Additionally, as presented in Figure 3, there is a high impact of IoE technology on significant marketing activities. As can be seen, the average rate is above $75 \%$. The values were obtained using data from interviews with experts. This value shows the high impact of IoE technology on the main parts of marketing and its sustainable development.

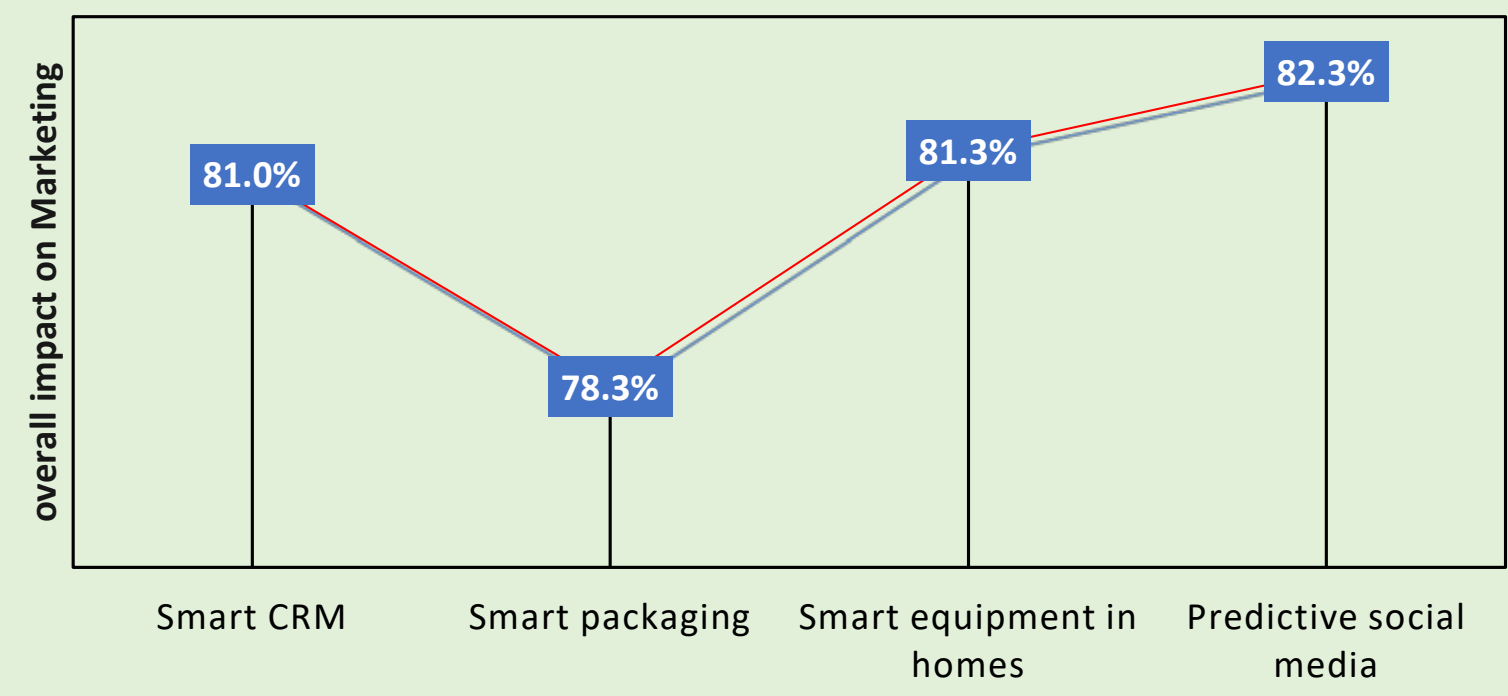

Influential components of IoE

Figure 3. The overall average impact of IoE usage on marketing in the dairy industry.

\section{Discussion}

The topic of this article is significant from a few points of view presenting the current economic situation, sudden changes, as well as long-term trends:

- The development of the Internet of Things;

- The development of the overall digitization of the global economy;

- The development of the dairy industry;

- Effects of sudden changes such as the COVID-19 pandemic;

- The development and growing impact of sustainable development, including sustainable marketing (and within it green marketing as well), in the life of residents and operations of companies;

- The development of the glocalization (globalization + localization) of production, customer demands, etc.

The dairy industry is a specific part of the FMCG industry because of (usually) the short expiration date of products, cold chain requirements, different consumers' habits, further access to milk, and many others [60,61,72]. Therefore, supply chain management in this industry requires reliable tools for managing the flows of goods [61]. IoT can deliver those, but its development and a growing number of integrated objects lead to the emergence of the IoE $[69,71]$. Marketing is one of the possible areas where IoE can be used, and nowadays, the focus is on communicating the robust targeting on sustainability [6] and green lifestyle [82]. Within sustainable marketing, being green is crucial. Therefore, using IoT and IoE in sustainable marketing is justified, as confirmed by [19].

However, no study strictly addressed this issue, which was also mentioned in the Introduction section of this paper. Looking at the scientific databases, with keywords of "sustainable marketing" or "green marketing" and "food" or "dairy" and "Internet of Things", proved that even its usefulness is not addressed by the researchers. The most 
similar to the current issue were two studies about blockchain technology in agri-food supply chains [83] and sustainable technologies in agri-food 4.0 [84], and some more, but only in the area of smart packaging, specifically in the dairy industry $[58,85,86]$. Therefore, it is worth discussing how to improve supply chain management methods and concepts by using IoT and IoE solutions. Since they will improve the way of using resources in the dairy industry, especially when the demand is very vulnerable, demand and supply shocks are caused by sudden events such as pandemics and products of the sector expire in the short term [87] (see also Table 6).

Table 6. The similarity of cited research results of other researchers up to 2021.

\begin{tabular}{ccccccc}
\hline Paper & Year & Marketing & IoE & IoT & Sustainability & Framework \\
\hline$[88]$ & 2021 & $\checkmark$ & $\times$ & $\checkmark$ & $\checkmark$ & $\times$ \\
{$[89]$} & 2021 & $\checkmark$ & $\times$ & $\checkmark$ & $\times$ & $\times$ \\
{$[90]$} & 2021 & $\checkmark$ & $\times$ & $\times$ & $\checkmark$ & $\times$ \\
{$[91]$} & 2020 & $\checkmark$ & $\times$ & $\checkmark$ & $\times$ & $\times$ \\
{$[16]$} & 2020 & $\checkmark$ & $\times$ & $\checkmark$ & $\times$ & $\times$ \\
{$[92]$} & 2020 & $\checkmark$ & $\times$ & $\checkmark$ & $\times$ & $\checkmark$ \\
[45] & 2011 & $\checkmark$ & $\times$ & $\times$ & $\checkmark$ & $\checkmark$ \\
\hline
\end{tabular}

The experts perceived performance as the essential factor in developing IoE-based sustainable marketing. Companies need to invest vast amounts of money in digitization [93], and their performance provides both the funds for the investments and chances for its maintenance and further development. The most critical areas of impact within this factor were those directly related to the income of dairy companies-smart equipment at home (e.g., fridges) and smart CRM software, as mentioned in the papers of [17,36,52]. It will be developed into more big data-based solutions such as supply chain control towers [52,94]. Income translates into the profit and the funds for further investment, brand market values, and others [95].

The experts' second most important factor, predictive social media, acts as the leading facilitator of marketing activities within the activity factor. Social media are the leading market force right now $[25,66,92,96]$, especially in younger groups of potential customers, with growing purchasing power and influence in the older cohorts, as confirmed by $[97,98]$. Furthermore, predictive media also affect changes in lifestyles. For example, people are more aware of healthy diets and the value of dairy products in building a healthy and long life $[60,99]$.

Facilitation was an exciting factor taken into consideration, not having any dominating area of impact. Therefore, the finding can be that all the identified areas in experts' opinions were equally important. If so, then they facilitate using IoE in sustainable marketing in the dairy industry.

\section{Conclusions}

In today's world, with the development of technology, the ways of producing big data are increasing. Objects and people create large datasets by connecting to the Internet. On the other hand, IoE technology can play an important role in sustainability and sustainable development. Therefore, understanding the dimensions of this technology, its relationship with sustainable development, and how to use it to develop sustainable marketing can play a valuable role in improving processes and facilitating marketing activities. It can also be a step towards environmental sustainability. Hence, in this study, besides the connection and valuable role of IoE technology with sustainable marketing, a framework is proposed to provide an effective map in understanding the relationship between these concepts.

This paper examines the dimensions, components, and impact indicators of IoE and the crucial role that technology plays in the marketing environment. In addition to determining the impact rate, these indicators are extracted based on the opinions of 
experienced experts. This research has been tested in a case study in the dairy industry as one of the most important industries in FMCG. A framework has been presented to show the relationship between influential factors and then validated based on experts' opinions. Of course, many studies presented in the literature have examined the role and dimensions of using artificial intelligence technologies and their effects on digital marketing $[11,17,89,100]$. Still, so far, other papers have not emphasized the effects of IoE on marketing and have not provided a conceptual model for it.

With the development of technology, the human ability to understand and use the vast amount of data around it increases every day. IoE technology goes beyond IoT technology, connecting everything to the Internet. Therefore, understanding and using this concept in all dimensions can play an influential role in developing processes and activities. Using this technology and understanding the key dimensions and components and effectively using the data produced can create marketing power to create value. Testing this technology in the dairy industry's marketing as a valuable part of daily life can increase the credibility of using IoE in sustainable development.

Environmental sustainability is one of the most important concepts that companies should consider. One of the most powerful tools for understanding the customer needs of organizations and satisfying the green demand is sustainable marketing, to which companies should pay particular attention. IoE tools allow organizations to collect and analyze large volumes of data, which can be used, monetized, and can improve overall system performance to deliver new types of services. This paper highlights the latest advanced research efforts in sustainable marketing and their relevance to digital technologies. Specifically, three research areas, including the architecture and framework of green and sustainable marketing, IoE architecture and communication protocols, and data management techniques, are examined in detail. In addition, the main research challenges for the successful deployment of IoE-based sustainable marketing are identified. This study concludes that the success of this smart and sustainable marketing system can be achieved if companies will address the key challenges, which include designing efficient data management programs, analytical and flexible big data technologies, and trusting IoE systems. Providing the right solutions can address these challenges. This study can be used as a guide to address some of the unresolved modern marketing challenges.

If so, this paper has theoretical (research) implications and practical ones. The research implications lie in creating a framework for IoE usage in the dairy industry or, more broadly, in FMCG industries. However, it was only a case study based on the opinions of a limited number of experts, so it should be verified in future research. For sure, this will be carried out since the pace of technological development is very fast. If talking about the managerial implications, the findings of this study can inform decision-makers (e.g., managers or marketing staff), especially from the discussed industry. Furthermore, knowledge about the factors that are relevant in building modern digital marketing can be taken into consideration. Moreover, sustainable development and customers' requirements about green businesses, green products, and minimizing the environmental impact are determined.

The value of this paper lies in the uniqueness of the topic, not mentioned in the same form in any literature source. The authors hope that the findings of this study will start a new direction of scientific discussion about IoE in today's business, especially in the times of online work and life in the COVID-19 pandemic era, besides the robotization and digitization of everything in socio-economic systems.

Author Contributions: Conceptualization, A.S.-J., J.G.-N. and H.N.; methodology, A.S.-J. and H.N.; software, H.N.; validation, J.G.-N.; formal analysis, A.S.-J.; investigation, A.S.-J., J.G.-N. and H.N.; resources, A.S.-J., J.G.-N. and H.N.; data curation, H.N.; writing-original draft preparation, A.S.J., J.G.-N. and H.N.; writing—review and editing, A.S.-J., J.G.-N. and H.N.; visualization, H.N.; supervision, A.S.-J.; project administration, A.S.-J. and H.N.; funding acquisition, A.S.-J. All authors have read and agreed to the published version of the manuscript. 
Funding: This research received no external funding.

Data Availability Statement: Not Applicable, the study does not report any data.

Acknowledgments: The authors want to thank the experts for dedicating time to a series of interviews leading to the completion of this paper and the whole, broader study.

Conflicts of Interest: The authors declare no conflict of interest.

\section{Appendix A}

Table A1. The impact of IoE technology on impact factors based on expert opinions.

\begin{tabular}{|c|c|c|c|}
\hline Smart CRM & Smart Packaging & $\begin{array}{l}\text { Smart Equipment in } \\
\text { Homes }\end{array}$ & $\begin{array}{c}\text { Predictive Social } \\
\text { Media }\end{array}$ \\
\hline $83 \%$ & $79 \%$ & $79 \%$ & $82 \%$ \\
\hline $81 \%$ & $78 \%$ & $82 \%$ & $82 \%$ \\
\hline $84 \%$ & $78 \%$ & $81 \%$ & $83 \%$ \\
\hline $80 \%$ & $76 \%$ & $81 \%$ & $80 \%$ \\
\hline $84 \%$ & $80 \%$ & $79 \%$ & $83 \%$ \\
\hline $82 \%$ & $76 \%$ & $82 \%$ & $81 \%$ \\
\hline $81 \%$ & $76 \%$ & $82 \%$ & $80 \%$ \\
\hline $81 \%$ & $78 \%$ & $82 \%$ & $82 \%$ \\
\hline $83 \%$ & $78 \%$ & $82 \%$ & $84 \%$ \\
\hline $82 \%$ & $76 \%$ & $82 \%$ & $82 \%$ \\
\hline $79 \%$ & $77 \%$ & $80 \%$ & $82 \%$ \\
\hline $80 \%$ & $76 \%$ & $80 \%$ & $81 \%$ \\
\hline $82 \%$ & $77 \%$ & $81 \%$ & $84 \%$ \\
\hline $84 \%$ & $77 \%$ & $81 \%$ & $84 \%$ \\
\hline $83 \%$ & $79 \%$ & $79 \%$ & $81 \%$ \\
\hline $80 \%$ & $76 \%$ & $82 \%$ & $82 \%$ \\
\hline $79 \%$ & $77 \%$ & $80 \%$ & $84 \%$ \\
\hline $81 \%$ & $79 \%$ & $79 \%$ & $84 \%$ \\
\hline $80 \%$ & $78 \%$ & $81 \%$ & $83 \%$ \\
\hline $80 \%$ & $75 \%$ & $79 \%$ & $80 \%$ \\
\hline $79 \%$ & $79 \%$ & $80 \%$ & $80 \%$ \\
\hline $81 \%$ & $75 \%$ & $81 \%$ & $82 \%$ \\
\hline $84 \%$ & $75 \%$ & $79 \%$ & $82 \%$ \\
\hline $81 \%$ & $79 \%$ & $82 \%$ & $84 \%$ \\
\hline $83 \%$ & $75 \%$ & $82 \%$ & $81 \%$ \\
\hline $81 \%$ & $79 \%$ & $81 \%$ & $83 \%$ \\
\hline $84 \%$ & $78 \%$ & $80 \%$ & $81 \%$ \\
\hline $79 \%$ & $78 \%$ & $80 \%$ & $82 \%$ \\
\hline $83 \%$ & $78 \%$ & $81 \%$ & $84 \%$ \\
\hline $81 \%$ & $79 \%$ & $82 \%$ & $82 \%$ \\
\hline $81 \%$ & $76 \%$ & $81 \%$ & $84 \%$ \\
\hline $80 \%$ & $75 \%$ & $79 \%$ & $80 \%$ \\
\hline $82 \%$ & $80 \%$ & $82 \%$ & $83 \%$ \\
\hline $79 \%$ & $80 \%$ & $80 \%$ & $81 \%$ \\
\hline $80 \%$ & $80 \%$ & $79 \%$ & $80 \%$ \\
\hline $80 \%$ & $78 \%$ & $79 \%$ & $82 \%$ \\
\hline $84 \%$ & $76 \%$ & $82 \%$ & $80 \%$ \\
\hline $80 \%$ & $78 \%$ & $82 \%$ & $80 \%$ \\
\hline $79 \%$ & $78 \%$ & $80 \%$ & $82 \%$ \\
\hline $80 \%$ & $77 \%$ & $81 \%$ & $83 \%$ \\
\hline
\end{tabular}

\section{References}

1. Han, H. Theory of green purchase behavior (TGPB): A new theory for sustainable consumption of green hotel and green restaurant products. Bus. Strateg. Environ. 2020, 29, 2815-2828. [CrossRef]

2. Yu, J.; Park, J.; Lee, K.; Han, H. Can environmentally sustainable development and green innovation of hotels trigger the formation of a positive brand and price premium? Int. J. Environ. Res. Public Health 2021, 18, 3275. [CrossRef] 
3. Hamid, S.; Jameel, S.T. A Study of Green Marketing Practices in the Selected Ayurvedic Resorts of Kerala. In Global Developments in Healthcare and Medical Tourism; IGI Global: Hershey, PA, USA, 2019.

4. Kasilingam, R. Opportunities and challenges in green marketing. Stud. Indian Place Names 2020, 1, 3412-3415.

5. Szmelter, A. Sustainable development as a factor shaping logistics strategies in global supply chains. Gospod. Mater. Logistyka 2016, 1261, 773-784.

6. Nosratabadi, S.; Mosavi, A.; Shamshirband, S.; Zavadskas, E.K.; Rakotonirainy, A.; Chau, K.W. Sustainable business models: A review. Sustainability 2019, 11, 1663. [CrossRef]

7. Seretny, M.; Gaur, D. The Model of Sustainable Marketing as a Responsible Approach to Marketing in the Era of Industry 4.0. In Advances in Science, Technology and Innovation; Springer: Cham, Switzerland, 2020.

8. Mohanraj, G.; Karthikeyan, P. Green marketing-New opportunities and challenges. Asian J. Res. Soc. Sci. Humanit. 2016, 6, 1238-1244. [CrossRef]

9. Andrienko, G.; Gunopulos, D.; Ioannidis, Y.; Kalogeraki, V.; Katakis, I.; Morik, K.; Verscheure, O. Mining urban data (Part C). Inf. Syst. 2017, 64. [CrossRef]

10. Caragliu, A.; del Bo, C.; Nijkamp, P. Smart cities in Europe. J. Urban Technol. 2011, 18, 65-82. [CrossRef]

11. Hanssens, D.M. AI, Marketing Science and Sustainable Profit Growth. In The Future of Management in an AI World; Palgrave Macmillan: London, UK, 2020.

12. Ziółkowska, M.J. Digital transformation and marketing activities in small and medium-sized enterprises. Sustainability 2021, 13, 2512. [CrossRef]

13. Saura, J.R.; Palacios-Marqués, D.; Iturricha-Fernández, A. Ethical design in social media: Assessing the main performance measurements of user online behavior modification. J. Bus. Res. 2021, 129, 271-281. [CrossRef]

14. Bhavana, A.; Thiruchanuru, S. Green marketing: Gap analysis in the decision making process of a green consumer. J. Bus. Manag. Soc. Sci. Res. 2018, 7, 50-57.

15. Schmitt, J. Creating Sustainable Value by Closing the Green Gap. 2021. Available online: https://academ.escpeurope.eu/pub/ IP\%202021-41-EN.pdf (accessed on 7 October 2021).

16. Weng, W.H. Internet of things utilization in marketing for competitive advantage: An organizational capability perspective. Proc. Int. Conf. Electron. Bus. 2020, 2020, 200-209.

17. Saura, J.R.; Ribeiro-Soriano, D.; Palacios-Marqués, D. Setting B2B digital marketing in artificial intelligence-based CRMs: A review and directions for future research. Ind. Mark. Manag. 2021, 98, 161-178. [CrossRef]

18. Diez-Martin, F.; Blanco-Gonzalez, A.; Prado-Roman, C. Research challenges in digital marketing: Sustainability. Sustainability 2019, 11, 2839. [CrossRef]

19. Saura, J.R.; Palos-Sanchez, P.; Herráez, B.R. Digital marketing for sustainable growth: Business models and online campaigns using sustainable strategies. Sustainability 2020, 12, 1003. [CrossRef]

20. Fonseca, L.M.; Azevedo, A.L. COVID-19: Outcomes for global supply chains. Manag. Mark. Chall. Knowl. Soc. 2020, 15, 424-438. [CrossRef]

21. Bamberger, V.; Nansé, F.; Schreiber, B.; Zintel, M. Logistics 4.0-Facing digitalization-driven disruption. Prism 2017, $38,39$.

22. Bechtold, J.; Lauenstein, C.; Kern, A.; Bernhofer, L. Industry 4.0: The capgemini consulting view. Capgemini Consult. Digit. Transform. Supply Chain. 2011, 1-36. Available online: https:/ /www.capgemini.com/consulting/wp-content/uploads/sites/30 /2017/07/capgemini-consulting-industrie-4.0_0_0.pdf (accessed on 7 October 2021).

23. Wilkinson, R.; Black, J.; Agnew, A.; Arnold, J.; Francolini, A.; Gardner, M.; Harder, A. Rethinking the value chain. Consum. Goods Forum 2015, 1, 48.

24. Rowan, N.J.; Galanakis, C.M. Unlocking challenges and opportunities presented by COVID-19 pandemic for cross-cutting disruption in agri-food and green deal innovations: Quo Vadis? Sci. Total Environ. 2020, 748, 141362. [CrossRef]

25. Eze, O.; Cherish, O.C. Achieving customer satisfaction through sustainable marketing strategies: A Qualitative analysis of three bread industries in Abakaliki Ebonyi State, Nigeria. Am. J. Multidiscip. Res. Dev. 2019, 1, 01-07.

26. Suchanek, M.; Szmelter-Jarosz, A. Environmental aspects of generation Y's sustainable mobility. Sustainability 2019, 11, 3204. [CrossRef]

27. Marzouk, O.A. A qualitative examination of urban vs. rural sustainable consumption behaviours of energy and water consumers in the emerging Egyptian market. J. Humanit. Appl. Soc. Sci. 2019, 1. [CrossRef]

28. Andronie, M.; Gârdan, D.A.; Dumitru, I.; Gârdan, I.P.; Andronie, I.E.; Uţă, C. Integrating the principles of green marketing by using big data. Good practices. Amfiteatru Econ. 2019, 21. [CrossRef]

29. Burritt, R.L.; Christ, K.L.; Rammal, H.G.; Schaltegger, S. Multinational enterprise strategies for addressing sustainability: The need for consolidation. J. Bus. Ethics 2020, 164, 389-410. [CrossRef]

30. Agustini, M.H.; Athanasius, S.S.; Retnawati, B.B. Identification of green marketing strategies: Perspective of a developing country. Innov. Mark. 2019, 15. [CrossRef]

31. Shabbir, M.S.; Sulaiman, M.A.B.A.; Al-Kumaim, N.H.; Mahmood, A.; Abbas, M. Green marketing approaches and their impact on consumer behavior towards the environment-A study from the UAE. Sustainability 2020, 12, 8977. [CrossRef]

32. Nieuwenhuijsen, M.J. Urban and transport planning, environmental exposures and health-new concepts, methods and tools to improve health in cities. Environ. Health Glob. Access Sci. Source 2016, 15, 161-171. [CrossRef] 
33. Muposhi, A.; Dhurup, M.; Surujlal, J. The green dilemma: Reflections of a GEneration Y consumer cohort on green purchase behaviour. J. Transdiscipl. Res. S. Afr. 2015, 11, 225-240. [CrossRef]

34. Cabato, M.G.; Macadat, Y.; Bronola, F.B. Green Marketing: A Study on the Perception of CBA Students in PUP Manila; Polytechnic University of the Phillipines, College of Business Administration: Maynila, Philippines, 2020.

35. Rejeb, A.; Simske, S.; Rejeb, K.; Treiblmaier, H.; Zailani, S. Internet of things research in supply chain management and logistics: A bibliometric analysis. Internet Things 2020, 12. [CrossRef]

36. Tariq, B.; Taimoor, S.; Najam, H.; Law, R.; Hassan, W.; Han, H. Generating marketing outcomes through Internet of things (Iot) technologies. Sustainability 2020, 12, 9670. [CrossRef]

37. Da Costa, V.C.F.; Oliveira, L.; de Souza, J. Internet of everything (IoE) taxonomies: A survey and a novel knowledge-based taxonomy. Sensors 2021, 21, 568. [CrossRef]

38. Auger, A.; Exposito, E.; Lochin, E. Towards the Internet of Everything: Deployment Scenarios for a QoO-Aware Integration Platform. In Proceedings of the IEEE World Forum on Internet of Things, WF-IoT 2018-Proceedings, Singapore, 5-8 February 2018.

39. Ilyas, M. Determining critical success factors for quality and accreditation through Delphi technique. Int. J. High. Educ. 2019, 8, 148-158. [CrossRef]

40. Xu, G.; Shi, Y.; Sun, X.; Shen, W. Internet of things in marine environment monitoring: A review. Sensors 2019, 19, 1711. [CrossRef]

41. Daú, G.; Scavarda, A.; Scavarda, L.F.; Portugal, V.J.T. The healthcare sustainable supply chain 4.0: The circular economy transition conceptual framework with the corporate social responsibility mirror. Sustainability 2019, 11, 3259. [CrossRef]

42. Srinivasan, C.R.; Rajesh, B.; Saikalyan, P.; Premsagar, K.; Yadav, E.S. A review on the different types of Internet of things (IoT). J. Adv. Res. Dyn. Control Syst. 2019, 11, 154-158.

43. Raj, A.; Prakash, S. Internet of Everything: A survey based on Architecture, Issues and Challenges. In Proceedings of the 2018 5th IEEE Uttar Pradesh Section International Conference on Electrical, Electronics and Computer Engineering, UPCON 2018, Gorakhpur, India, 2-4 November 2018.

44. Arseculeratne, D.; Yazdanifard, R. How green marketing can create a sustainable competitive advantage for a business. Int. Bus. Res. 2013, 7, 130-137. [CrossRef]

45. Gordon, R.; Carrigan, M.; Hastings, G. A framework for sustainable marketing. Mark. Theory 2011, 11. [CrossRef]

46. Yin, R.K. Case study research: Desing and methods. Appl. Soc. Res. Methods Ser. 2003, 5. [CrossRef]

47. Madoranova, M.; Horvath, M. Multi-criteria decision matrix approach for supplier evaluation in micro and small organizations. Qual. Innov. Prosper. 2013, 17, 120-127. [CrossRef]

48. Blome, C.; Schoenherr, T. Supply chain risk management in financial crises-A multiple case-study approach. Int. J. Prod. Econ. 2011, 134, 43-57. [CrossRef]

49. Clift, R.; Druckman, A. Taking Stock of Industrial Ecology; Springer: Cham, Switzerland, 2016; ISBN 9783319205700.

50. Bashir, H.; Jørgensen, S.; Jacob, L.; Pedersen, T.; Skard, S. Experimenting with sustainable business models in fast moving consumer goods. J. Clean. Prod. 2020, 270, 122302. [CrossRef]

51. Kayikci, Y. Sustainability impact of digitization in logistics. Proc. Manuf. 2018, 21, 782-789. [CrossRef]

52. Pfeiffer, C. The Internet of Things: A Marketing Tool for the Food Industry? Bachelor's Thesis, University of Twente, Entschede, The Netherlands, 2018; pp. 1-15.

53. Nozari, H.; Fallah, M.; Kazemipoor, H.; Najafi, S.E. Big data analysis of IoT-based supply chain management considering FMCG industries. Bus. Inform. 2021, 15. [CrossRef]

54. Končar, J.; Grubor, A.; Marić, R.; Vučenović, S.; Vukmirović, G. Setbacks to IoT implementation in the function of FMCG supply chain sustainability during COVID-19 pandemic. Sustainability 2020, 12, 7391. [CrossRef]

55. Eisenhardt, K.M. Theory building from cases: Opportunities and challenges. Acad. Manag. J. 2007, 50, 25-32. [CrossRef]

56. Steenhuis, H.-J.; de Bruijn, E.J. Building Theories from Case Study Research: The Progressive Case Study. In Proceedings of the OM in the New World Uncertainties. In Proceedings of the 17th Annual Conference of POMS, (CD-ROM), Boston, MA, USA, 28 April-1 May 2006; pp. 1-13.

57. Saliya, C.A. Doing qualitative case study research in business management. Case Stud. J. 2017, 6, 96-111.

58. Kr Deshwal, G.; Raju Panjagari, N. Active and Intelligent Packaging of Cheese: Developments and Future Scope. In Food Packaging; IntechOpen: London, UK, 2021.

59. Scimeca, J. COVID-19 and crisis planning: A learning experience. Dairy Foods 2020, 22. Available online: https:/ / www.dairyfoods. com/articles/94285-covid-19-and-crisis-planning-a-learning-experience (accessed on 7 October 2021).

60. Wang, J.; Yue, H. Food safety pre-warning system based on data mining for a sustainable food supply chain. Food Control 2017, 73 . [CrossRef]

61. Al-Zabidi, A.; Rehman, A.U.; Alkahtani, M. An approach to assess sustainable supply chain agility for a manufacturing organization. Sustainability 2021, 13, 1752. [CrossRef]

62. Corbin, J.; Strauss, A. Grounded theory research: Procedures, canons, and evaluative criteria. Qual. Sociol. 1990, $13,3-21$. [CrossRef]

63. Christopoulos, D.C. Peer Esteem Snowballing: A Methodology for Expert Surveys. In Proceedings of the Eurostat Conference for New Techniques and Technologies for Statistics; Eurostat: Brussels, Belgium, 2009; pp. 171-179. 
64. Trotter, R.T. Qualitative research sample design and sample size: Resolving and unresolved issues and inferential imperatives. Prev. Med. 2012, 55, 398-400. [CrossRef]

65. Corbin, J.; Strauss, A. Basics of Qualitative Research: Techniques and Procedures for Developing Grounded Theory, 3rd ed.; Sage publications: New York, NY, USA, 2012.

66. Egilman, D.; Druar, N.M. Spin your science into gold 1: Direct to consumer marketing within social media platforms. Work 2012, 41, 4494-4502. [CrossRef]

67. Shokouhyar, S.; Pahlevani, N. Scenario analysis of smart, sustainable supply chain on the basis of a fuzzy cognitive map. Manag. Res. Rev. 2020, 43, 463-496. [CrossRef]

68. Lee, B.; Cooper, R.; Hands, D.; Coulton, P. Design Drivers: A Critical Enabler to Meditate Value over the NPD Process within Internet of Things. In Proceedings of the Style Template for 4D Designing Development, Developing Design Conference, Osaka, Japan, 21-23 October 2019; pp. 1-12. Available online: https://eprints.lancs.ac.uk/id/eprint/139453/1/201910_4D_1_.pdf (accessed on 7 October 2021).

69. Leonardi, S. Internet of Things (IoT) and Dairy Farm Automation. Ph.D. Thesis, Università degli Studi di Milano, Milan, Italy, 2014.

70. Tian, F. An information System for Food Safety Monitoring in Supply Chains based on HACCP, Blockchain and Internet of Things. Ph.D. Thesis, WU Vienna University of Economics and Business, Vienna, Austria, 2018.

71. Vate-u-lan, P.; Quigley, D.; Masoyras, P. Smart dairy farming through the Internet of Things (IoT). Asian Int. J. Soc. Sci. 2016, 17, 23-36. [CrossRef]

72. Dabbaghi, Z.; Bahramimianrood, B. Selection of factors affecting the supply chain and green suppliers by the TODIM method in the dairy industry. J. Sci. Manag. Tour. 2021, 2021,1-6.

73. Fereday, J.; Muir-Cochrane, E. Demonstrating rigor using thematic analysis: A hybrid approach of inductive and deductive coding and theme development. Int. J. Qual. Methods 2006, 5, 80-92. [CrossRef]

74. Alhojailan, M.I.; Ibrahim, M. Thematic analysis: A critical review of its process and evaluation. WEI Int. Eur. Acad. Proc. 2012, 1, 8-21.

75. Kendall, J. Axial coding and the grounded theory controversy. West. J. Nurs. Res. 1999, 21, 743-757. [CrossRef]

76. Awasthi, A.; Adetiloye, T.; Crainic, T.G. Collaboration partner selection for city logistics planning under municipal freight regulations. Appl. Math. Model. 2016, 40. [CrossRef]

77. Lin, X.M.; Ho, C.H.; Xia, L.T. Analysis of image and molding of sharing bicycle frame in urban traffic efficiency based on fuzzy theory. Ekoloji Dergisi 2018, 27, 1161-1166.

78. Zakeri, S.; Keramati, M.A. Systematic combination of fuzzy and grey numbers for supplier selection problem. Grey Syst. Theory Appl. 2015, 5, 313-343. [CrossRef]

79. Guo, S.; Zhao, H. Fuzzy best-worst multi-criteria decision-making method and its applications. Knowl. Based Syst. 2017. [CrossRef]

80. Nozari, H.; Najafi, E.; Fallah, M.; Lotfi, F.H. Quantitative analysis of key performance indicators of green supply chain in FMCG industries using non-linear fuzzy method. Mathematics 2019, 7, 1020. [CrossRef]

81. Chen, T.; Wang, Y.-C.; Wu, H.-C. Analyzing the impact of vaccine availability on alternative supplier selection amid the COVID-19 pandemic: A cFGM-FTOPSIS-FWI approach. Healthcare 2021, 9, 71. [CrossRef]

82. Hopkins, D. Can environmental awareness explain declining preference for car-based mobility amongst generation Y? A qualitative examination of learn to drive behaviours. Transp. Res. Part A Policy Pract. 2016, 94, 149-163. [CrossRef]

83. Saurabh, S.; Dey, K. Blockchain technology adoption, architecture, and sustainable agri-food supply chains. J. Clean. Prod. 2021, 284. [CrossRef]

84. Miranda, J.; Ponce, P.; Molina, A.; Wright, P. Sensing, smart and sustainable technologies for Agri-Food 4.0. Comput. Ind. 2019, 108. [CrossRef]

85. Sani, M.A.; Azizi-Lalabadi, M.; Tavassoli, M.; Mohammadi, K.; McClements, D.J. Recent advances in the development of smart and active biodegradable packaging materials. Nanomaterials 2021, 11, 1331. [CrossRef]

86. Karaman, A.D.; Özer, B.; Pascall, M.A.; Alvarez, V. Recent advances in dairy packaging. Food Rev. Int. 2015, 31. [CrossRef]

87. Goh, S.H.; Woong, J.Y. Supply Chain Risk Management Strategies in the Face of COVID-19. In Proceedings of the 11th Annual International Conference on Industrial Engineering and Operations Management, Singapore, 7-11 March 2021.

88. Zeinalizadeh, R.; Ebadati, E.O.M.; Jafari, M.A. Sustainable marketing strategy for smart energy networks based on implementation of general science and technology policies. Q. J. Macro Strateg. Policies 2021, 1-10. [CrossRef]

89. Moradi, M. Importance of internet of things (IoT) in marketing research and its ethical and data privacy challenges. Bus. Ethics Leadersh. 2021, 5. [CrossRef]

90. Romprasert, S.; Trivedi, A.; Trivedi, A. Sustainable economy on community enterprise and digital marketing. ABAC J. 2021, 41, 62-80.

91. Miskiewicz, R. Internet of things in marketing: Bibliometric analysis. Mark. Manag. Innov. 2020, 3, 371-381. [CrossRef]

92. Maiorescu, I.; Bucur, M.; Georgescu, B.; Moise, D.; Strat, V.A.; Zgura, I.D. Social media and IOT wearables in developing marketing strategies. Do SMEs differ from large enterprises? Sustainability 2020, 12, 7292. [CrossRef]

93. Wilkesmann, M.; Wilkesmann, U. Industry 4.0-Organizing routines or innovations? VINE J. Inf. Knowl. Manag. Syst. 2018. [CrossRef] 
94. Pearson, M. Supply chain control towers are taking off. Logist. Manag. 2014, 53, 26-27.

95. Khan, Z.; Lew, Y.K.; Park, B. Institutional legitimacy and norms-based CSR marketing practices: Insights from MNCs operating in a developing economy. Int. Mark. Rev. 2015, 32, 5. [CrossRef]

96. Dillon, B. Marketing Travel to Millennials: Is Social Media the Ticket? University of Minnesota: Minneapolis, MN, USA, 2016; pp. 1-128.

97. McDonald, N.C. Are millennials really the "go-Nowhere" Generation? J. Am. Plan. Assoc. 2015, 81, 90-103. [CrossRef]

98. Haustein, S.; Klöckner, C.A.; Blöbaum, A. Car use of young adults: The role of travel socialization. Transp. Res. Part F Traffic Psychol. Behav. 2009, 12, 168-178. [CrossRef]

99. Siren, A.; Haustein, S. Baby boomers' mobility patterns and preferences: What are the implications for future transport? Transp. Policy 2013, 29, 136-144. [CrossRef]

100. Kang, J.; Diao, Z.; Zanini, M.T. Business-to-business marketing responses to COVID-19 crisis: A business process perspective. Mark. Intell. Plan. 2020. [CrossRef] 